\title{
Ribonucleotide reductase M2 is a promising molecular target for the treatment of oral squamous cell carcinoma
}

\author{
KAZUKI IWAMOTO, KOH-ICHI NAKASHIRO, HIROSHI TANAKA, \\ NORIHIKO TOKUZEN and HIROYUKI HAMAKAWA
}

\begin{abstract}
Department of Oral and Maxillofacial Surgery, Ehime University Graduate School of Medicine, Toon, Ehime 791-0295, Japan
\end{abstract}

Received December 2, 2014; Accepted January 30, 2015

DOI: 10.3892/ijo.2015.2912

\begin{abstract}
In our previous study, ribonucleotide reductase M2 (RRM2) was identified as a cancer-related gene commonly overexpressed in human oral squamous cell carcinoma (OSCC) cell lines. Herein, we attempted to determine whether targeting RRM2 may be a plausible therapeutic approach for the treatment of patients with OSCC. First, we examined the expression levels of RRM2 in human OSCC cell lines and tissues. Overexpression of RRM2 in OSCC was confirmed by western blot analysis. Subsequently, we investigated the effects of a synthetic small interfering RNA specific for RRM2 and gemcitabine (GEM), an inhibitor of RRM2 enzymatic activity, on the growth of human OSCC cell lines and primary cultured cells. Targeting RRM2 by RNA interference almost completely suppressed the expression of RRM2 and markedly suppressed the growth of both types of cells by $>54.8 \%$. GEM also reduced the growth rate of these cells by $>83.0 \%$. Finally, we evaluated the antitumor effects of GEM, cisplatin (CDDP), 5-fluorouracil (5-FU), and docetaxel (DOC) against OSCC cells using the collagen gel droplet embedded culture drug sensitivity test. OSCC cells were more sensitive to GEM and DOC than to CDDP and 5-FU, regardless of the expression level of RRM2 mRNA. These results suggested that RRM2 supported the growth of human OSCC cells and that targeting of RRM2, e.g., via GEM treatment, may be a promising therapeutic strategy for OSCC.
\end{abstract}

Correspondence to: Dr Koh-Ichi Nakashiro, Department of Oral and Maxillofacial Surgery, Ehime University Graduate School of Medicine, 454 Shitsukawa, Toon, Ehime 791-0295, Japan

E-mail: nakako@m.ehime-u.ac.jp

Abbreviations: CD-DST, collagen gel droplet embedded culture drug sensitivity test; GEM, gemcitabine; HNSCC, head and neck squamous cell carcinoma; OSCC, oral squamous cell carcinoma; RRM2, ribonucleotide reductase M2; siRRM2, small interfering RNA specific for RRM2

Key words: oral squamous cell carcinoma, ribonucleotide reductase M2, gemcitabine, collagen gel droplet embedded culture drug sensitivity test, chemotherapy

\section{Introduction}

More than 500,000 new cases of head and neck squamous cell carcinoma (HNSCC) occurred in 2008 worldwide. Oral squamous cell carcinoma (OSCC) is the most frequently occurring cancer among HNSCCs and is associated with a mortality rate of approximately 50\%, as reported in 2008 (1). Despite the increasing knowledge of OSCC pathogenesis, as well as advances in chemotherapy, radiotherapy, and surgery, little improvement in the relative survival rate has been observed in OSCC during the past several decades (2). Therefore, a greater understanding of the pathogenesis of OSCC is needed for the development of optimal therapeutic approaches.

Cancer cells acquire abnormalities in multiple oncogenes and tumor-suppressor genes. Overexpression and constitutive activation of some oncogenes support the proliferation, invasion, and metastasis of cancer cells. Inactivation of a single critical oncogene can induce cancer cells to differentiate into cells with a normal phenotype or to undergo apoptosis. This dependence on oncogenes for maintaining the cancer phenotype is an Achilles heel for cancer cells, which can be exploited in cancer therapy (3).

In HNSCCs, including OSCC, the overexpression of epidermal growth factor receptor (EGFR) correlates with lymph node metastasis, risk of locoregional recurrence, and poor prognosis $(4,5)$. Cetuximab, which targets EGFR, is used for patients with local advanced, recurrent, or metastatic HNSCC. Radiotherapy or platinum-based chemotherapy plus cetuximab improve locoregional control and overall survival $(6,7)$. However, cetuximab is the only available molecular targeted drug for the treatment of OSCC. Thus, we previously attempted to identify useful target molecules for the treatment of OSCC using microarray analysis, and we identified 465 cancer-related genes that were commonly overexpressed in human OSCC cell lines (8). Among these genes, overexpression of ribonucleotide reductase M2 (RRM2), which is targeted by gemcitabine (GEM), has been shown to be involved in tumor progression in human malignancies (9).

Ribonucleotide reductase (RR) catalyzes the conversion of ribonucleotide 5'-diphosphates to their 2'-deoxynucleotide form required for DNA synthesis. RRM2 is the catalytic subunit of RR and modulates its enzymatic activity (10-12). GEM binds to RRM2, replaces cytidine during DNA replication, and 
inhibits RR, hence reducing deoxynucleotide pools; moreover, GEM also competes with deoxycytidine triphosphate for incorporation into elongating DNA strands and halts DNA polymerization (13). GEM has been used for the treatment of pancreatic cancer, biliary tract cancer, lung cancer, breast cancer, bladder cancer, and ovarian cancer. Furthermore, GEM has been applied in preclinical and clinical studies for head and neck cancer including OSCC (14-19).

Therefore, in this study, we examined the role of RRM2 in OSCC using GEM, which targets RRM2, and RNA interference (RNAi). Our data show that RRM2 is an important molecular target that is involved in the pathogenesis of OSCC and that it could be a promising target for the treatment of OSCC.

\section{Materials and methods}

Cells and cell culture. We used four human OSCC cell lines: green fluorescent protein (GFP)-SAS (20), Ca9-22, HSC2, and HSC3, as previously described (21). All cell lines were maintained in Dulbecco's modified Eagle's medium (DMEM; Wako, Osaka, Japan) supplemented with $10 \%$ fetal bovine serum (FBS; Biosource, Camarillo, CA, USA), 100 U/ml penicillin, and $100 \mu \mathrm{g} / \mathrm{ml}$ streptomycin (Wako), referred to here as complete medium. Primary cultured cells were established from OSCC tumors harvested from patients. Tumor tissues, including adjacent normal tissues, were surgically excised and rinsed several times with complete medium. The tumor and adjacent normal tissues were individually cut into small fragments and dissociated at $37^{\circ} \mathrm{C}$ for $2 \mathrm{~h}$ with $0.1 \%$ collagenase (Wako). The cell suspension was filtered through a cell strainer with 70- $\mu$ m nylon mesh (BD, Franklin Lakes, NJ, USA). The cells were collected by centrifugation, resuspended in keratinocyte serum-free medium (K-SFM; Life Technologies, Carlsbad, CA, USA), seeded onto plastic tissue culture dishes, and grown in an incubator with a humidified atmosphere of $95 \%$ air and $5 \% \mathrm{CO}_{2}$ at $37^{\circ} \mathrm{C}$.

Small molecule compound. Gemcitabine hydrochloride (GEM; Wako) was dissolved in nuclease-free water to a stock concentration of $10 \mathrm{mM}$ and stored at $4^{\circ} \mathrm{C}$ until use.

Samples from patients. Twenty-five OSCC tissues from patients were obtained at the Ehime University Hospital from September 2008 to May 2014. The tissues were collected from resected specimens of primary tumors (17 men and 8 women; average age, 68.04 years). Three primary cultured cells were derived from OSCC of the lower gingiva (from a 55-year-old man, T4N2bM0), tongue (from a 57-year-old man, rT1N0M0), and skin metastasis (from a 61-year-old man, rT0N0M1). The Institutional Review Board (IRB) at Ehime University Hospital approved this study. All patients were enrolled after providing written informed consent.

Western blot analysis. Cells (5x10 5 for GFP-SAS, Ca9-22, HSC2, and HSC3) were grown in monolayers and lysed with lysis buffer [0.5 M EDTA (Dojindo, Kumamoto, Japan) and 1\% NP-40 (Nacalai Tesque, Kyoto, Japan) in phosphate-buffered saline (PBS; Wako) containing a protease inhibitor and phosphatase inhibitor (Roche Diagnostics, Basel, Switzerland)].
Tissues were homogenized in $500 \mu 1$ of lysis buffer with the use of a TissueLyser system (Qiagen, Valencia, CA, USA). The samples were centrifuged at $15,000 \mathrm{x}$ g for $15 \mathrm{~min}$ at $4^{\circ} \mathrm{C}$, and supernatants were electrophoresed on SDS-polyacrylamide gels, followed by transfer to polyvinylidene difluoride membranes (Millipore, Bedford, MA, USA). The membranes were blocked with $5 \%$ nonfat dried milk (Wako) in $1 \mathrm{X}$ TBS-T [25 mM Tris- $\mathrm{HCl}, 125 \mathrm{mM} \mathrm{NaCl}$, and $0.1 \%$ Tween-20 (Sigma-Aldrich, St. Louis, MO, USA)] for $15 \mathrm{~min}$ at $37^{\circ} \mathrm{C}$. Membranes were then probed with monoclonal mouse antihuman RRM2 antibodies (Abnova, Taipei, Taiwan; diluted $1: 500)$ or monoclonal mouse anti- $\beta$-tubulin antibodies (BD; diluted 1:1000) in 5\% nonfat dried milk in 1X TBS-T for $1 \mathrm{~h}$ at room temperature, followed by treatment with horseradish perioxidase-conjugated secondary antibodies against mouse IgG (GE Healthcare, Buckinghamshire, UK) for $1 \mathrm{~h}$ at room temperature. The immune complexes were visualized using enhanced chemiluminescence (ECL) Prime western blotting detection reagent (GE Healthcare). The density of visualized immune complexes was quantified using an LAS-3000 system (Fujifilm, Tokyo, Japan).

Transfection with synthetic small interfering RNA (siRNA). We used Silencer Select siRNA targeting RRM2 (siRRM2) and Silencer Select Negative Control (siNT) purchased from Life Technologies. Transfections were performed with Lipofectamine RNAiMAX (Life Technologies) mixed with $5 \mathrm{nM}$ siRNAs for western blotting and cell growth assays.

Cell growth assay. Cells (2x10 ${ }^{3}$ GFP-SAS cells, $3 \times 10^{3}$ Ca9-22, HSC2, and HSC3 cells) were seeded into 96-well plates in complete medium with $5 \mathrm{nM}$ synthetic siRNAs and $0.2 \%$ Lipofectamine RNAiMAX in a final volume of $100 \mu$ l. GEM was added to each well at different concentrations ranging from 1 to $1000 \mathrm{nM}$. After $72 \mathrm{~h}$, cell growth was evaluated by WST-8 assay (Cell Counting Kit-8; Dojindo).

In vitro collagen gel droplet embedded culture drug sensitivity test $(C D-D S T)$. The chemosensitivity of OSCC was evaluated using CD-DST kit (Primastar ${ }^{\circledR}$; Kurabo, Osaka, Japan) according to manufacturer's protocol as described previously (22). The anticancer drugs tested in the CD-DST were GEM (Eli Lilly Japan, Kobe, Japan; $8.0 \mu \mathrm{g} / \mathrm{ml}$ for $1 \mathrm{~h}$ ), cisplatin (CDDP; Bristol-Myers Squibb, Tokyo, Japan; $0.2 \mu \mathrm{g} / \mathrm{ml}$ for $24 \mathrm{~h}$ ), 5-fluorouracil (5-FU; Kyowa Hakko Kirin, Tokyo, Japan; $1.0 \mu \mathrm{g} / \mathrm{ml}$ for $24 \mathrm{~h}$ ) and $0.1 \mu \mathrm{g} / \mathrm{ml}$ docetaxel (DOC; Sanofi, Tokyo, Japan; $0.1 \mu \mathrm{g} / \mathrm{ml}$ for $24 \mathrm{~h}$ ). In vitro sensitivity was expressed as the $\mathrm{T} / \mathrm{C}(\%)$, where $\mathrm{T}$ was the total volume of the treated group and $\mathrm{C}$ was the total volume of the control group. A T/C of $50 \%$ or less to each anticancer drug was regarded as in vitro sensitive (23).

Real-time quantitative reverse transcriptional polymerase chain reaction $(q R T-P C R)$. Total RNA was extracted by lysing OSCC tissues with ISOGEN reagent (NipponGene, Toyama, Japan) after homogenization with a TissueLyser (Qiagen). The relative quantity of mRNA was determined using SYBR Green and the comparative CT method $(\Delta \mathrm{CT}$ method). Hydroxymethylbilane synthase (HMBS) was used as an internal control. PCR amplification was performed 
A

(kDa)
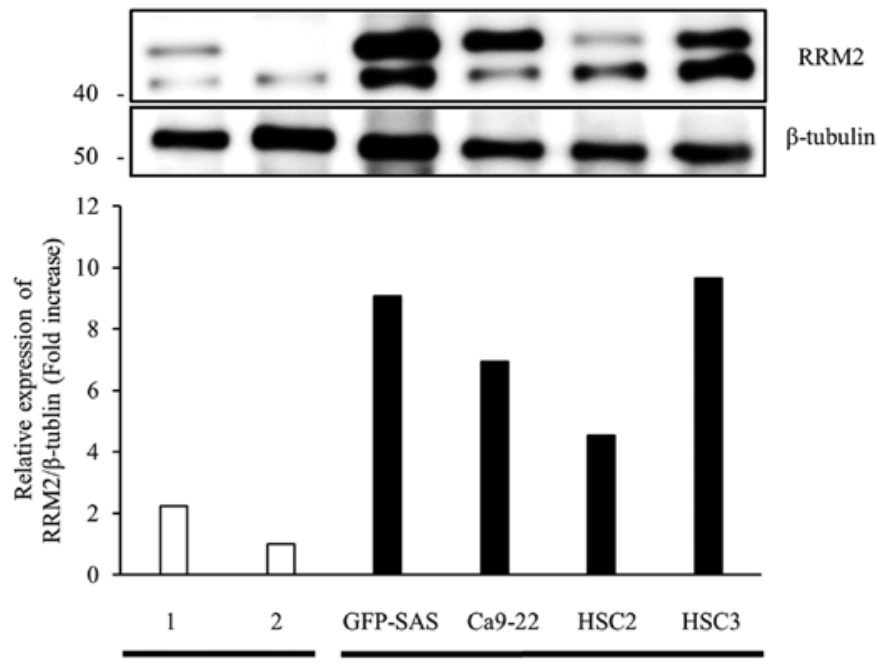

B

Human normal oral mucosa epithelial Human OSCC cell lines primary cultured cells

(kDa)

$40-$
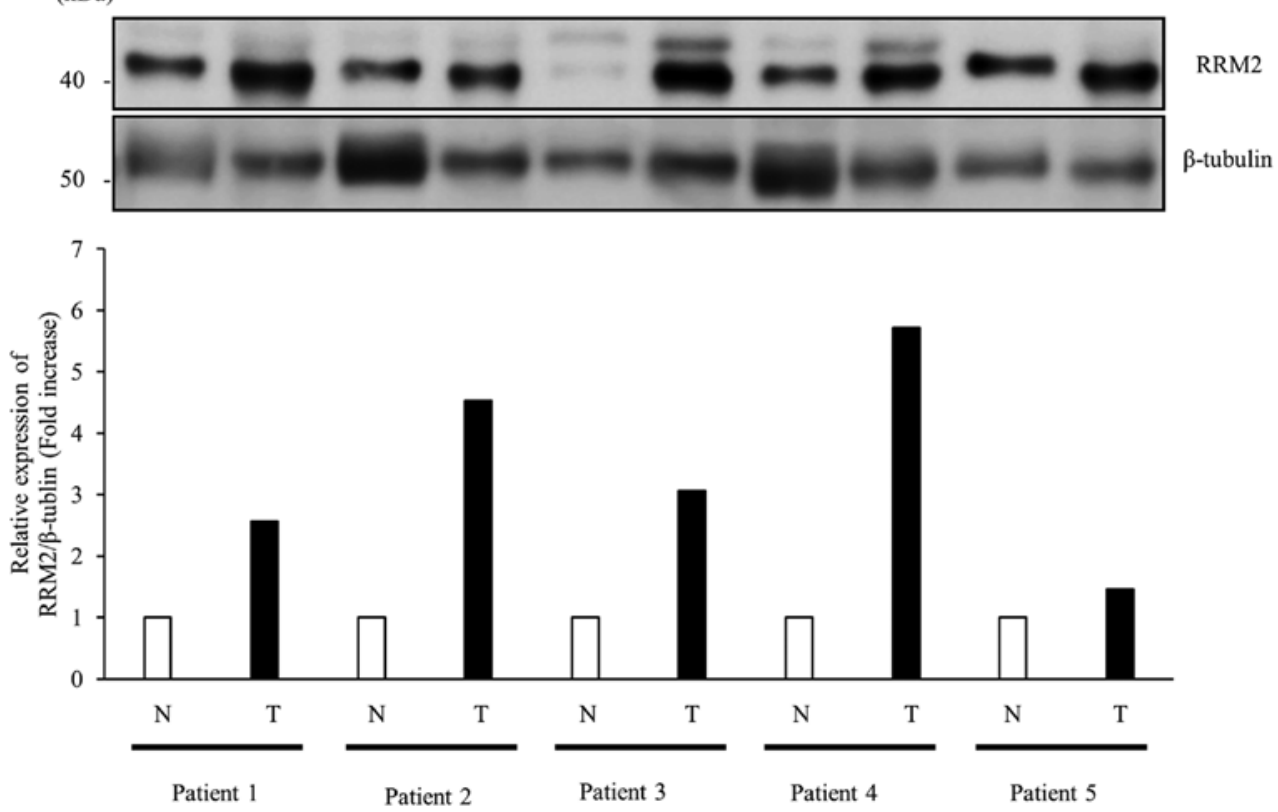

Figure 1. Expression of RRM2 protein in OSCC. (A) RRM2 protein expression in human OSCC cells was detected by western blotting. RRM2 protein is shown as two bands, with the upper band indicating phosphorylated RRM2. (B) RRM2 protein expression in the tumors and adjacent normal tissues from the same patient, as analyzed by western blotting. N, normal tissues; T, tumor tissues.

in a $10 \mu \mathrm{l}$ final reaction mixture containing $5 \mu \mathrm{l}$ of $2 \mathrm{X}$ One Step SYBR RT-PCR Buffer 4, $0.4 \mu 1$ of PrimeScript One Step Enzyme Mix 2 (Takara, Otsu, Japan), $0.4 \mu 1$ of PCR forward and reverse primers $(10 \mu \mathrm{M}), 0.2 \mu \mathrm{l}$ of ROX reference Dye II (x50), $2.6 \mu \mathrm{l}$ of RNase-free $\mathrm{dH}_{2} \mathrm{O}$, and $1 \mu \mathrm{l}$ of total RNA (100 ng/ $\mu \mathrm{l})$. The thermal-cycling conditions were as follows: reverse transcription at $42^{\circ} \mathrm{C}$ for $5 \mathrm{~min}$ and $95^{\circ} \mathrm{C}$ $10 \mathrm{sec}$, followed by 40 cycles at $95^{\circ} \mathrm{C}$ for $5 \mathrm{sec}$ and $60^{\circ} \mathrm{C} 30 \mathrm{sec}$. SYBR Green I fluorescence was detected with ViiA ${ }^{\mathrm{TM}} 7$ (Life Technologies). The sequences of primers used were as follows: RRM2: forward 5'-TGC GTC GAT ATT CTG GCT CAA G-3' and reverse 5'-CCG ATG GTT TGT GTA CCA GGT G-3'; HMBS: forward 5'-CAT GCA GGC TAC CAT CCA TGT C-3' and reverse 5'-GTT ACG AGC AGT GAT GCC TAC CAA-3'.
Statistical analysis. All in vitro experiments were performed in triplicate and repeated three times. All statistical analyses were performed using GraphPad Prism software, version 5.04 (GraphPad Software, San Diego, CA, USA). Student's t-tests were used to determine the significance of differences between the groups. Log-rank tests were used to analyze survival rates. Differences with P-values of $<0.05$ were considered statistically significant.

\section{Results}

Overexpression of RRM2 protein in OSCC. First, we examined the expression of RRM2 protein in four human OSCC cell lines and human normal oral mucosa epithelial primary cultured cells 
A

$(\mathrm{kDa})$
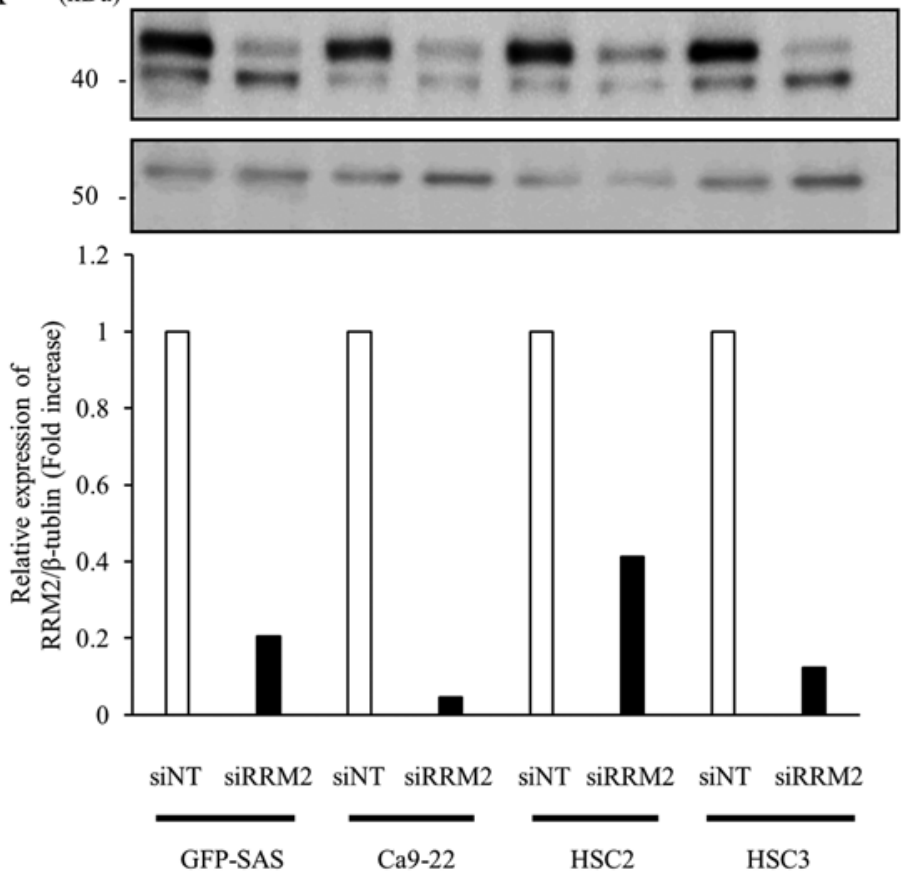

C
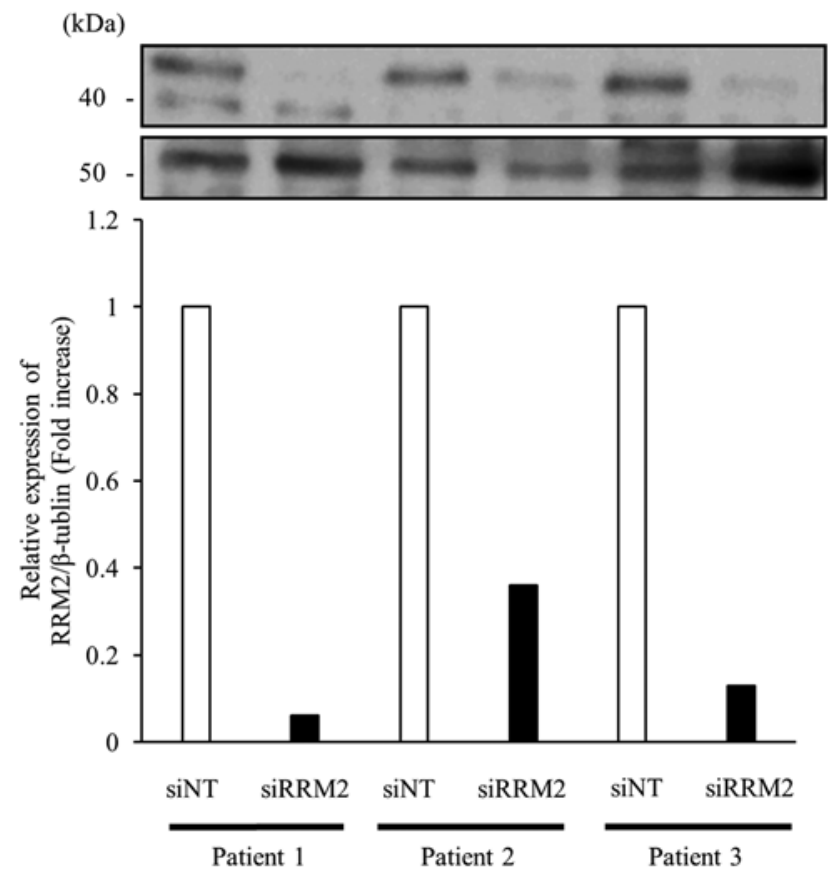

B

RRM2 $\beta$-tubulin

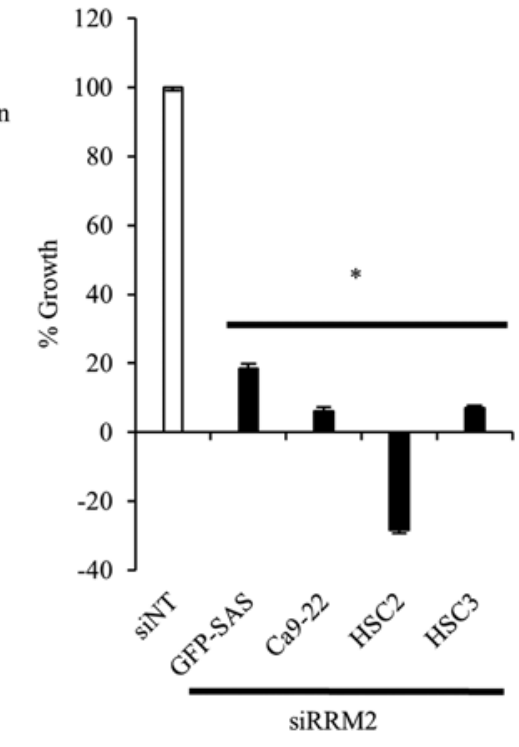

D
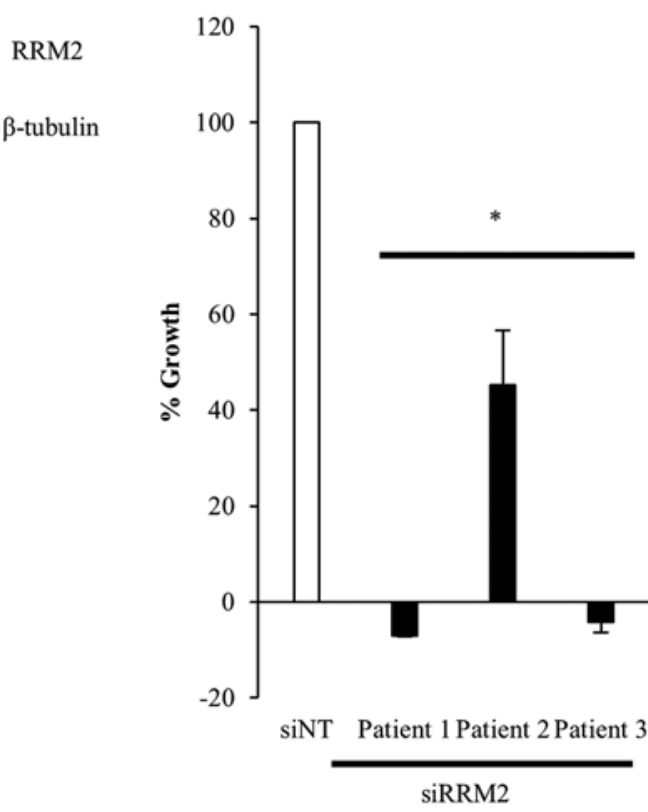

Figure 2. Growth inhibitory effects of siRRM2 in human OSCC cells in vitro. (A and C) Synthetic siRRM2 (5 nM) was transfected into human OSCC cell lines (GFP-SAS, Ca9-22, HSC2, and HSC3) and three primary cultured cells using Lipofectamine RNAiMAX for 24 h. (B and D) Human OSCC cells were seeded in complete medium with synthetic siRNAs for $72 \mathrm{~h}$, and cell growth was analyzed. Bars denote the standard deviations (SDs) of samples analyzed in triplicate. ${ }^{*} \mathrm{P}<0.01$ compared to control culture. siNT, non-targeting siRNA.

by western blotting. The expression levels of RRM2 protein in all OSCC cells were $>2$-fold higher than those in human normal oral mucosa epithelial cells (Fig. 1A). Subsequently, we compared the expression levels of RRM2 protein in OSCC tumors and adjacent normal mucosa tissues from the same patient; in these samples, we found 1.5- to 5.7-fold higher expression in RRM2 protein in tumor tissues than in normal tissues (Fig. 1B). Thus, these data supported that RRM2 protein was overexpressed in OSCC tissues and cultured cells.
Growth inhibitory effects of siRRM2 in human OSCC cells in vitro. To clarify the function of RRM 2 in the proliferation of human OSCC cells, we transfected GFP-SAS, Ca9-22, HSC2, and HSC 3 cells with $5 \mathrm{nM}$ siRRM2. Targeting RRM 2 by RNAi suppressed the expression of RRM 2 protein by $>58 \%$ compared to siNT and significantly inhibited the growth of human OSCC cell lines by $>81.5 \%$ (Fig. $2 \mathrm{~A}$ and B). Furthermore, in primary cultured cells obtained from culture of resected tumor tissues from OSCC patients, knockdown of RRM2 expression also 

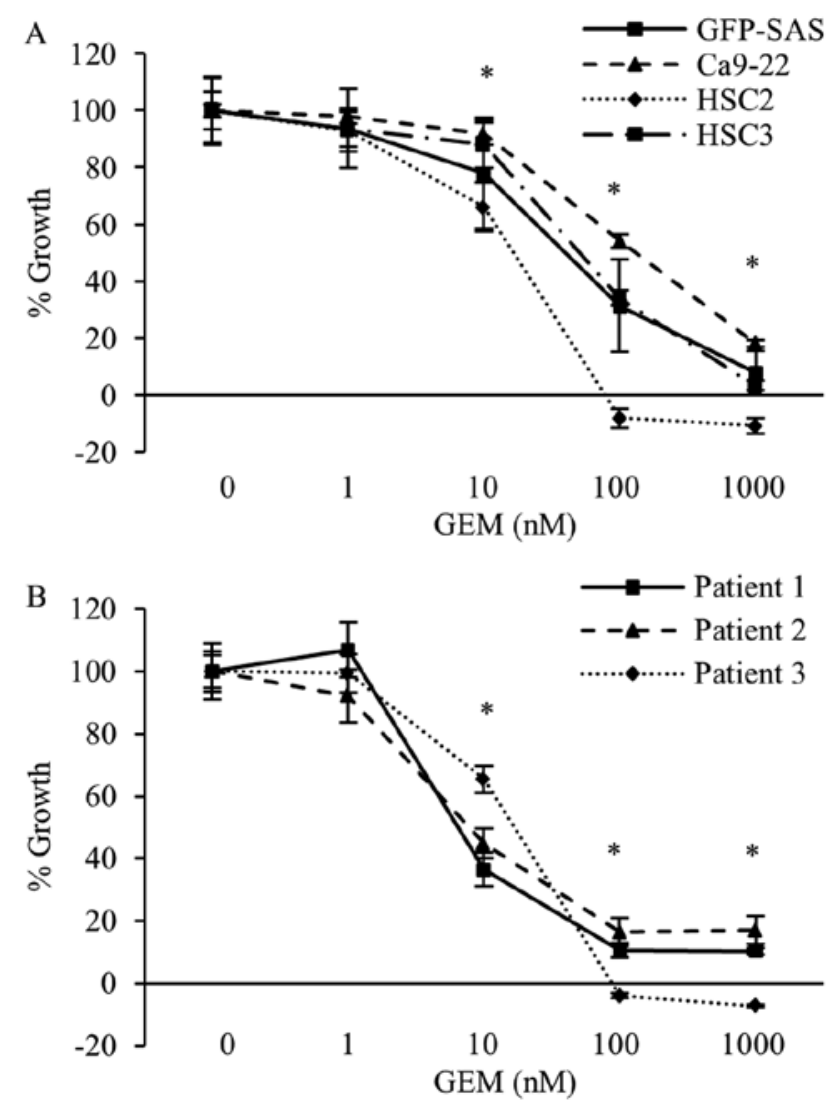

Figure 3. Antiproliferative effects of GEM in human OSCC cells in vitro. Human OSCC cell lines, i.e., GFP-SAS, Ca9-22, HSC2 and HSC3 (A), and three primary cultured cells (B) were seeded in complete medium. Twentyfour hours later, GEM was added to each well at final concentrations of 0,1 , 10,100 , or $1000 \mathrm{nM}$. After $72 \mathrm{~h}$, cell viability was evaluated by WST- 8 assay Bars denote the SDs of samples analyzed in triplicate. ${ }^{*} \mathrm{P}<0.01$ compared to the control culture.

suppressed the growth of OSCC primary cultured cells by $>54.8 \%$ (Fig. 2C and D).

Antitumor effects of GEM in human OSCC cells in vitro. Next, we examined the effects of GEM on the inhibition of RRM2 activity on the growth of human OSCC cell lines and primary cultured cells. In both types of cells, GEM markedly reduced the cell growth rate in a concentration-dependent manner. The growth rate of all OSCC cells was decrease $>83.0 \%$ following treatment with $1000 \mathrm{nM} \mathrm{GEM} \mathrm{(Fig.} \mathrm{3A} \mathrm{and} \mathrm{B).}$

In vitro chemosensitivity of OSCC. Next, we evaluated the chemosensitivity of 25 OSCC tumors to GEM, CDDP, 5-FU, and DOC using CD-DST. From this analysis, we found that 16 cases $(64 \%)$ were sensitive to GEM, with an average T/C value of $42.6 \%$. OSCC tumors were more sensitive to GEM and DOC than to CDDP and 5-FU (Table I).

Clinical significance of GEM sensitivity and RRM2 $\mathrm{mRNA}$ expression in OSCC. Finally, we examined RRM $2 \mathrm{mRNA}$ expression levels by qRT-PCR in OSCC cases and investigated the relationship between GEM sensitivity, RRM 2 mRNA expression levels, and prognosis (overall, disease-specific and disease-free survival) in OSCC cases. However, there were
Table I. CD-DST in OSCC cases $(\mathrm{n}=25)$.

\begin{tabular}{lcccc}
\hline Anticancer drugs & GEM & CDDP & 5-FU & DOC \\
\hline Average T/C (\%) & $42.6 \pm 30.5$ & $73.5 \pm 21.7$ & $82.4 \pm 17.5$ & $41.1 \pm 24.5$ \\
Sensitive case (n) & 16 & 1 & 5 & 18 \\
P-value & & $<0.001$ & $<0.001$ & 0.697
\end{tabular}

A $\mathrm{T} / \mathrm{C}$ of $50 \%$ or less to each anticancer drug was regarded as sensitive. CD-DST, collagen gel droplet embedded culture drug sensitivity test; GEM, gemcitabine; CDDP, cisplatin; 5-FU, 5-fluorouracil; DOC, docetaxel; T/C, total colony volume of the treated cells/total colony volume of the untreated cells.

no significant correlations or differences among these factors (data not shown).

\section{Discussion}

In this study, we examined the expression and function of RRM2 in OSCC. Our data demonstrated that RRM2 was overexpressed in OSCC cells and primary culture cells derived from patient tumors and that inhibition of RRM2 via GEM or siRRM2 suppressed cell growth of OSCC cells. Thus, RRM2 may represent a novel target for anticancer therapy in OSCC.

RRM2 overexpression has been shown to be significantly associated with tumor progression or survival in many types of cancer (9,24-26). Ectopic expression of RRM2 induces membrane-associated Raf1 expression and MAPK2 and Rac-1 activation, resulting in enhanced metastatic potential in a xenograft model (27). In addition, a previous study showed that HNSCC cells overexpress RRM2 and that knockdown of RRM2 by RNAi significantly reduces the growth of HNSCC cells in vitro and in vivo (28). Herein, we showed that RRM2 was overexpressed in OSCC and demonstrated the growth inhibitory effects of targeting RRM2 by RNAi in human OSCC cells. A recent study showed that knockdown of RRM2 expression promotes apoptosis by suppressing Bcl-2 protein expression in HNSCC and non-small cell lung cancer (NSCLC) cells. RRM2 suppression contributes to the instability of Bcl-2 or causes $\mathrm{Bcl}-2$ to remain unprotected from degradation. Thus, RRM2 may be an attractive interventional target to downregulate $\mathrm{Bcl}-2$, resulting in the induction of mitochondria-mediated intrinsic apoptosis (26). Therefore, targeting RRM2 may be an appropriate therapeutic approach for the treatment of these cancers.

GEM, triapine, and GTI-2040 are known RRM2 inhibitors (29-31). Triapine and GTI-2040 have been evaluated in phase I clinical trials $(30,31)$. GEM competes with RRM2 for replicating DNA and is a potential candidate for RRM2 inhibition that has been approved by the US Food and Drug Administration for the treatment of NSCLC, pancreatic cancer, ovarian cancer, and breast cancer. However, GEM has not been approved for the treatment of OSCC.

Currently, CDDP-based chemotherapy is generally the first-line treatment for inoperable recurrent or metastatic OSCC because we cannot predict the efficacy of chemotherapy. CD-DST can mimic in vivo tumor growth using 
type I collagen to create a three-dimensional culture system and individually evaluate the response to chemotherapeutic drugs. Several clinical studies have reported that CD-DST may be useful when devising optimal treatment strategies for NSCLC (23), ovarian (32), gastrointestinal (33), or colon cancer (34). In patients with HNSCC, CD-DST can be also used to predict CDDP sensitivity and guide individualized chemotherapy (35). Thus, CD-DST has been approved for use in the evaluation of cancer treatments by the Ministry of Health, Labour and Welfare of Japan. In the present study, CD-DST indicated that GEM and DOC had more potent antitumor activity against OSCC than CDDP and 5-FU. CDDP plus 5-FU (PF) chemotherapy is the most widely used therapy in the treatment of patients with OSCC. The resistance of tumor cells to PF remains a major cause of treatment failure. Therefore, GEM may be a useful second-line chemotherapy for PF-resistant OSCC.

The relationship between $R R M 2$ mRNA expression levels and the response to GEM in the clinical setting has been investigated in various cancers. In pancreatic cancer, the response rate to GEM is significantly higher in patients with low RRM2 mRNA expression in biopsy specimens (36). Furthermore, in patients with lung adenocarcinoma, low levels of $R R M 2 \mathrm{mRNA}$ are associated with the response to GEM plus DOC (24). These results indicate the possibility that expression levels of $R R M 2$ mRNA could predict chemosensitivity to GEM. However, there was no significant correlation between GEM sensitivity and $R R M 2$ mRNA expression levels in patients with OSCC in this study. Thus, there is still no molecular marker available to predict the response to GEM in OSCC.

In conclusion, our data suggest that RRM2 plays a critical role in supporting the growth of human OSCC cells, and agents targeting RRM2, such as GEM, appear to be a potentially useful therapeutic approach for OSCC.

\section{Acknowledgements}

This work was supported, in part, by JSPS KAKENHI (grant no. 17689057).

\section{References}

1. Ferlay J, Shin HR, Bray F, Forman D, Mathers C and Parkin DM Estimates of worldwide burden of cancer in 2008: GLOBOCAN 2008. Int J Cancer 127: 2893-2917, 2010.

2. Gupta S, Kong W, Peng Y, Miao Q and Mackillop WJ: Temporal trends in the incidence and survival of cancers of the upper aerodigestive tract in Ontario and the United States. Int J Cancer 125: 2159-2165, 2009.

3. Weinstein IB: Cancer. Addiction to oncogenes - the Achilles heal of cancer. Science 297: 63-64, 2002.

4. Ang KK, Berkey BA, Tu X, Zhang HZ, Katz R, Hammond EH, $\mathrm{Fu}$ KK and Milas L: Impact of epidermal growth factor receptor expression on survival and pattern of relapse in patients with advanced head and neck carcinoma. Cancer Res 62: 7350-7356, 2002.

5. Rubin Grandis J, Melhem MF, Gooding WE, Day R, Holst VA, Wagener MM, Drenning SD and Tweardy DJ: Levels of TGF- $\alpha$ and EGFR protein in head and neck squamous cell carcinoma and patient survival. J Natl Cancer Inst 90: 824-832, 1998.

6. Bonner JA, Harari PM, Giralt J, et al: Radiotherapy plus cetuximab for squamous-cell carcinoma of the head and neck. N Engl J Med 354: 567-578, 2006.

7. Vermorken JB, Mesia R, Rivera F, et al: Platinum-based chemotherapy plus cetuximab in head and neck cancer. N Engl J Med 359: 1116-1127, 2008
8. Tanaka H, Nakashiro K, Iwamoto K, Tokuzen N, Fujita Y, Shirakawa R, Oka R, Goda H and Hamakawa H: Targeting Aurora kinase A suppresses the growth of human oral squamous cell carcinoma cells in vitro and in vivo. Oral Oncol 49: 551-559, 2013.

9. Furuta E, Okuda H, Kobayashi A and Watabe K: Metabolic genes in cancer: Their roles in tumor progression and clinical implications. Biochim Biophys Acta 1805: 141-152, 2010.

10. Duxbury MS, Ito H, Zinner MJ, Ashley SW and Whang EE: RNA interference targeting the M2 subunit of ribonucleotide reductase enhances pancreatic adenocarcinoma chemosensitivity to gemcitabine. Oncogene 23: 1539-1548, 2004.

11. Eriksson S and Martin DW Jr: Ribonucleotide reductase in cultured mouse lymphoma cells. Cell cycle-dependent variation in the activity of subunit protein M2. J Biol Chem 256: 9436-9440, 1981.

12. Thelander M, Gräslund A and Thelander L: Subunit M2 of mammalian ribonucleotide reductase. Characterization of a homogeneous protein isolated from M2-overproducing mouse cells. J Biol Chem 260: 2737-2741, 1985.

13. Plunkett W, Huang P, Xu YZ, Heinemann V, Grunewald R and Gandhi V: Gemcitabine: Metabolism, mechanisms of action, and self-potentiation. Semin Oncol 22 (Suppl 11): 3-10, 1995.

14. Aguilar-Ponce J, Granados-García M, Villavicencio V, et al: Phase II trial of gemcitabine concurrent with radiation for locally advanced squamous cell carcinoma of the head and neck. Ann Oncol 15: 301-306, 2004.

15. Braakhuis BJM, van Dongen GAMS, Vermorken JB and Snow GB: Preclinical in vivo activity of $2^{\prime}, 2^{\prime}$-difluorodeoxycytidine (Gemcitabine) against human head and neck cancer. Cancer Res 51: 211-214, 1991.

16. Senkal CE, Ponnusamy S, Rossi MJ, et al: Potent antitumor activity of a novel cationic pyridinium-ceramide alone or in combination with gemcitabine against human head and neck squamous cell carcinomas in vitro and in vivo. J Pharmacol Exp Ther 317: 1188-1199, 2006.

17. Saddoughi SA, Garrett-Mayer E, Chaudhary U, et al: Results of a phase II trial of gemcitabine plus doxorubicin in patients with recurrent head and neck cancers: Serum $\mathrm{C}_{18}$-ceramide as a novel biomarker for monitoring response. Clin Cancer Res 17: 6097-6105, 2011.

18. Fury MG, Haque S, Stambuk H, Shen R, Carlson D and Pfister D: A phase 2 study of pemetrexed plus gemcitabine every 2 weeks for patients with recurrent or metastatic head and neck squamous cell cancer. Cancer 117: 795-801, 2011.

19. van Herpen CML, Locati LD, Buter J, et al: Phase II study on gemcitabine in recurrent and/or metastatic adenoid cystic carcinoma of the head and neck (EORTC 24982). Eur J Cancer 44: 2542-2545, 2008.

20. Shintani S, Mihara M, Nakahara Y, Aida T, Tachikawa T and Hamakawa $\mathrm{H}$ : Lymph node metastasis of oral cancer visualized in live tissue by green fluorescent protein expression. Oral Oncol 38: 664-669, 2002.

21. Shintani S, Hamakawa H, Nakashiro K, Shirota T, Hatori M, Tanaka M, Kuroshita Y and Kurokawa Y: Friend leukaemia insertion (Fli)-1 is a prediction marker candidate for radiotherapy resistant oral squamous cell carcinoma. Int J Oral Maxillofac Surg 39: 1115-1119, 2010.

22. Kobayashi H, Higashiyama M, Minamigawa K, Tanisaka K, Takano T, Yokouchi H, Kodama K and Hata T: Examination of in vitro chemosensitivity test using collagen gel droplet culture method with colorimetric endpoint quantification. Jpn J Cancer Res 92: 203-210, 2001

23. Higashiyama M,Oda K,Okami J,Maeda J,Kodama K, Imamura F, Minamikawa K, Takano T and Kobayashi H: Prediction of chemotherapeutic effect on postoperative recurrence by in vitro anticancer drug sensitivity testing in non-small cell lung cancer patients. Lung Cancer 68: 472-477, 2010.

24. Souglakos J, Boukovinas I, Taron M, et al: Ribonucleotide reductase subunits $\mathrm{M} 1$ and M2 mRNA expression levels and clinical outcome of lung adenocarcinoma patients treated with docetaxel/gemcitabine. Br J Cancer 98: 1710-1715, 2008.

25. Morikawa T, Maeda D, Kume H, Homma Y and Fukayama M: Ribonucleotide reductase M2 subunit is a novel diagnostic marker and a potential therapeutic target in bladder cancer. Histopathology 57: 885-892, 2010.

26. Rahman MA, Amin ARMR, Wang D, et al: RRM2 regulates Bcl-2 in head and neck and lung cancers: A potential target for cancer therapy. Clin Cancer Res 19: 3416-3428, 2013. 
27. Fan H, Villegas $\mathrm{C}$ and Wright JA: Ribonucleotide reductase R2 component is a novel malignancy determinant that cooperates with activated oncogenes to determine transformation and malignant potential. Proc Natl Acad Sci USA 93: 14036-14040, 1996.

28. Rahman MA, Amin ARMR, Wang X, et al: Systemic delivery of siRNA nanoparticles targeting RRM2 suppresses head and neck tumor growth. J Control Release 159: 384-392, 2012.

29. Shao J, Zhou B, Chu B and Yen Y: Ribonucleotide reductase inhibitors and future drug design. Curr Cancer Drug Targets 6: 409-431, 2006.

30. Wadler S, Makower D, Clairmont C, Lambert P, Fehn K and Sznol M: Phase I and pharmacokinetic study of the ribonucleotide reductase inhibitor, 3-aminopyridine-2-carboxaldehyde thiosemicarbazone, administered by 96 -hour intravenous continuous infusion. J Clin Oncol 22: 1553-1563, 2004.

31. Desai AA, Schilsky RL, Young A, Janisch L, Stadler WM Vogelzang NJ, Cadden S, Wright JA and Ratain MJ: A phase I study of antisense oligonucleotide GTI-2040 given by continuous intravenous infusion in patients with advanced solid tumors. Ann Oncol 16: 958-965, 2005
32. Yabushita H, Ohnishi M, Komiyama M, Mori T, Noguchi M, Kishida T, Noguchi Y, Sawaguchi K and Noguchi M: Usefulness of collagen gel droplet embedded culture drug sensitivity testing in ovarian cancer. Oncol Rep 12: 307-311, 2004.

33. Mori S, Kunieda K, Sugiyama Y and Saji S: Prediction of 5-fluorouracil and cisplatin synergism for advanced gastrointestinal cancers using a collagen gel droplet embedded culture. Surg Today 33: 577-583, 2003

34. Mekata E, Sonoda H, Shimizu T, Tatsuta T, Yamaguchi T, Endo $\mathrm{Y}$ and Tani T: Clinical predictive value of in vitro anticancer drug sensitivity test for the therapeutic effect of adjuvant chemotherapy in patients with stage II-III colorectal cancer. Mol Clin Oncol 1: 763-767, 2013.

35. Zhang ZP, Sun YL, Fu L, Gu F, Zhang L and Hao XS: Correlation of Notch1 expression and activation to cisplatin-sensitivity of head and neck squamous cell carcinoma. Ai Zheng 28: 100-103, 2009.

36. Itoi T, Sofuni A, Fukushima N, Itokawa F, Tsuchiya T, Kurihara T, Moriyasu F, Tsuchida A and Kasuya K: Ribonucleotide reductase subunit M2 mRNA expression in pretreatment biopsies obtained from unresectable pancreatic carcinomas. J Gastroenterol 42 389-394, 2007. 